\title{
CORRESPONDENCE.
}

\section{MENDEL'S LAWS OF INHERITANCE AND WHEAT BREEDING.}

IN a paper dealing with the application of Mendel's Laws to wheatbreeding, I described a series of experiments which led me to conclude that immunity and susceptibility to the attacks of yellow rust form a pair of "characters" in the Mendelian sense of the word". The data were obtained from a single experiment, yet I felt that the only course open to me was to publish them at once, leaving the discussion of the problems this conception opens up until further evidence was available. One of the objects $I$ had in view in planning this particular part of the work was to determine whether there was any real hope of obtaining satisfactory rust-resistant wheats. From the breeder's point of view it appeared to me that if the mycoplasm hypothesis is true, i.e. if the young plant actually inherits the rust itself from its parent, this is not a promising line of research. Setting aside, therefore, for the time being any other views as to what constitutes immunity, I examined my results in the light of the mycoplasm hypothesis. As I pointed out, this failed to account for the fact that an immune wheat when crossed by a susceptible one gave rise to a susceptible progeny, though it was snfficient to explain the susceptibility of the hybrid obtained as the result of the reciprocal cross. I further speculated on the possibility of the generative nuclei bearing the hypothetical mycoplasm.

Butler, in a recent paper ${ }^{2}$, criticises my conclusions, and considers that they have no bearing on the mycoplasm hypothesis.

The following excerpts from Eriksson's latest publication on the subject of the mycoplasm hypothesis will, I think, save me from the necessity of discussing Butler's arguments in detail, and show that my criticism was not altogether irrelevant: "Wie die Sache jetzt liegt, scheint es mir gar nicht unmöglich oder unsinnig zu sein an eine

1 Biffen. Joum. Agric. Science, Vol. r. p. 40.

2 Butler. Joum. Agric. Science, Vol, I. p. 361. 
Erblichkeit der Krankheitsanlage auch dass männliche Organ, die Pollenkörner, zu denken," and further, "... so hat man wenigstens mit der Möglichkeit zu rechen, dass auch die Gewebe der Staubblätter, und zwar speziell die der Antheren, mycoplasma fiuhrend sein können.".

It is difficult to treat in detail one of the broad questions raised by Butler for lack of evidence one way or the other. It may at once be stated, however, that it is a well-recognized fact that immunity to yellow rust does not necessarily imply immunity to any other rust. Michigan Bronze, for instance, is intensely susceptible to yellow rust, but practically immune to black and brown rust. An inspection of the tables in Eriksson's Die Getreiderost ${ }^{2}$ will provide numerous other examples.

But the question as to how far characters alter with a change of locality is still an open one, which can only be answered by the cooperation of a number of workers in different districts. Its importance is so obvious that it may serve a useful purpose if I point out some of the typical difficulties already encountered in this part of the research. Butler's paper provides two examples out of the three he quotes as illustrating this possibility. The first is "the striking case of spelt wheat which has proved very resistant in some parts of India and not in others." Spelt wheat is a generic term, for there are a large number of varieties of spelts in cultivation. Thus in my own experiments I have had occasion to grow nearly thirty, some of which were obtained from India. Amongst those are some varieties which are the most immune to yellow rust I possess, whilst others are second only to Michigan Bronze in susceptibility. If, as I suspect, the evidence for this particular case rests on a generalization from the various spelt crops as seen here und there in the country it is of no particular value. To be satisfactory it would have to be based on a critical experiment with one variety distributed over various districts and kept under observation for a number of seasons. Of such an experiment I can, however, find no mention.

The second example is provided by the rust resistant hybrids raised by Farrar in New South Wales, which have proved susceptible in India. The question which at once arises is "Were they ever rust-resistant?" Had such varieties ever been tested for a sufficient number of years in Australia before being tried in India?

One has to be critical on such a point, for a variety of wheat may escape rust for a season or two and then, owing to conditions of which

1 Eriksson. Arkiv för Botanik, 1905, Bd. 5, p. 54.

2 For wheats, p. 333 et seq. ; for barleys, p. 344 et seq. 
we are ignorant, become badly attacked. That this has been the case with Farrar's hybrids is clear. Thus in a communication referring to the hybrid "Bobs," Farrar writes", "I mentioned that it was rust-free in 1903 at the Hawkesbury College Farm, and it was on that account that I suggested that we might have in it a variety which would prove to be sufe to grow in the coastal counties. In 1904, however, 'Bobs' failed to resist this pest at Richmond as well as other places in the county of Cumberland, but was in fact smitten hip and thigh by the pest...... Still the matter is disappointing; but it is nothing more, and this failure cannot be regarded as a final failure to get varieties which will withstand rust in the coastal counties."

Of the third case, that of Kathia wheat, I can find no further data as to its behaviour outside of the United States, but I think that enough has been said to make one cautious of the statement so frequently made that characters will alter with a change of locality. That physiological characters do so is clear in certain cases, but we badly need really definite evidence on this point with regard to rustresistance.

\section{R. H. BIFFEN.}

\section{THE SUPPLY OF NITRATE TO THE SURFACE SOLL FROM THE UNDERGROUND WATER.}

Is Mr A. D. Hall's interesting paper on the "Fertility of Land allowed to run wild"," he attributes a part of the accumulated nitrogen to "capillary creep" of nitrates from the underground water. In the present very imperfect state of our knowledge us to the actual velocity at which water moves vertically through the soil during dry weather, together with a corresponding absence of exact information regarding the diffusion of salts in the soil, it would be impossible to prove the truth of Mr Hall's assumption. But there are several arguments of a circumstantial nature, which may be advanced to disprove it.

In the first place these underground waters will contain chlorides as well as nitrates, and if the one be brought to the surface in the manner suggested so must the other. I do not know of any analyses of Rothamsted well waters, but usually such water contains at least

\footnotetext{
1 Farrar. Agric. Gaz. of N.S.W., 1905, p. 262.

3 Journ. Agric. Science, Vol. I. p. 241.
} 
several times as much chloride as nitrate, and indeed the disparity is commonly very great.

Mr Hall naturally does not suggest that any particular portion of the accumulated nitrogen in the soils is due to the underground water, but from the fact that this source is mentioned at all it is to be assumed that a material part of the whole is meant. Assuming such to be one-tenth, it would mean that of the 037 per cent. increase of nitrogen in the surface soil of the Broadbalk field, $\cdot 0037$ is referable to the supply in question, or of the 023 per cent. accumulation in the Geescroft surface soil, 0023 per cent. is from the same source. There is no need to consider the gains of nitrogen in the lower depths of the soil for the purpose in view.

If this underground water contains equivalent quantities of chloride, then there should be a similar accumulation of chlorine; or if, as is much more probable, the ratio of chlorine to nitrate-nitrogen in the underground water is $10: 1$ or even a wider ratio, then the accumulation of chlorine should be, say, $0037 \times 10=037$ or $0023 \times 10=023$ respectively. On this point $\mathrm{Mr}$ Hall's paper gives no information.

The quantity of chlorine in the Broadbalk and Hnos fields soil is, however, stated in the Lawes Agricultural Trust lectures by Dyer ${ }^{1}$, and there is, as a matter of fact, in the Broadbalk field somewhat more cbloride in the secoud depth of 9 inches than in the lower strata. The difference varies from one part to eight parts per million of soil, and for most plots it is only two or three. Eight parts per million is equal to .0008 per hundred of soil, and if only the unmanured plots are considered the quantity falls to 0001 per cent. chlorine. In the Hoos field there is no such increased quantity of chlorine in the second depth.

This is far smaller than the quantity of chloride which should be found if any material portion of the accumulated nitrogen in the uncultivated patch of Broadbalk field had been derived from underground water.

As a matter of fact there is no reason for supposing that the larger quantity of chloride in the second 9 inches of soil in the Broadbalk field was derived at all from underground water. The higher concentration in this depth is much more readily explained by the effects of season.

Then, too, if salts pass from the underground water to the surface and accumulate there, it means that on the whole a greater quantity of

1 United States Department of Agriculture, Office of Experiment Stations, Bulletin No. 106, 1902. 
salt moves annually in this direction than downwards. If this is so it follows that a greater quantity of water does likewise, and that there is a net loss of underground water, or in other words that the underground water is not derived from percolation at all but from some other source. It is, however, well established that in many or most situations the underground water is due solely to percolation.

There are also other arguments which may be advanced against the assumption that salts ever reach the surface from underground water, unless the latter is within 3 or $4 \mathrm{ft}$. of the surface.

One is that in any country with a rainfall distributed well over the year as in England, percolation is in progress more or less all the year through; such movement of water is much more rapid than the opposite one; and the resultant effect must be a general downward movement of the salts rather than the converse. Even in India, with five or six months of dry weather and a much higher temperature than that of Europe, it is not usual to find any accumulation of salts in the surface soil where the underground water contains high proportions of nitrates and chlorides. For, example, the very saline well waters of Gujarat', and Muttra ${ }^{2}$ are situated below very fertile and non-saline soils. Usar land is not here forgotten, but this special case does not negative the more common one. If the underground water happens to lie less than about $5 \mathrm{ft}$. from the surface, such an accumulation may occur, but these conditions are exceptional.

Again, the fact that the amount of evaporation is the same from the $20^{\prime \prime}$ and $60^{\prime \prime}$ gauges at Rothamsted is a proof that the underground water supply does not affect the amount of water evaporated, for if it. did the $60^{\prime \prime}$ gauge should lose more than the $20^{\prime \prime}$ gauge.

If the absence of accumulated chlorine were accounted for on the assumption that both this element and the nitrate do come with the underground water during dry weather, when the nitrate is arrested by vegetation, but that later with the next rain the chlorine is washed down again, such an argument implies that this can happen during such short dry periods as are experienced at Rothamsted; that also the whole of the water in the soil down to the underground water also passes in the same short period to the surface (and evaporates), and that during the next wet period enough rain falls to wash down again the accumulation of chloride and other salts to their original position at the underground water level. Such an assumption implies a movement

1 Vide Agricultural Ledger; No. 14 of 1895.

2 Vide Transactions of the Chemical Society, Vol, Lxxxi. 
of water far greater than actually occurs. Admittedly this velocity is not known with any great precision, but even the most extravagant of the various laboratory experiments which have been made to exhibit the rate of rise of water through soils, have not shown such a velocity as the foregoing case would require.

\section{J. WALTER LEATHER.}

I agree with Dr Leather that capillarity would bring up chlorides as well as nitrates, but on the first rainfall sufficient to cause percolation down would go the chlorides again, the nitrates having meantime been taken up by the crop. Mr Warington has shown ${ }^{1}$ that such returns of nitrate from the subsoil to the surface can take place. It is, however, arguable that capillary uplift will only bring back to the surface nitrates which had been made there and then washed down, but this ignores all possibility of diffusion or of lateral displacements of the whole body of soil water. How otherwise does a tree in a paved street get its nitrogen except by the lateral influx of nitrates in the soil water?

A. D. HALL.

1 Trans. Highland and Agric. Soc. 1905. 